Correspondence

Woong Shick Ahn

ahnlab1@catholic.ac.kr

Received 22 April 2010

Accepted 17 October 2010

\section{Evaluation of a liquid bead array system for high-risk human papillomavirus detection and genotyping in comparison with Hybrid Capture II, DNA chip and sequencing methods}

\author{
Eun Jung Cho, ${ }^{1}$ Jin Hwan Do, ${ }^{2}$ Yoon Sun Kim, ${ }^{2}$ Sumi Bae ${ }^{2}$ \\ and Woong Shick $\mathrm{Ahn}^{3}$ \\ ${ }^{1}$ Department of Anesthesiology, Catholic University of Korea, 505 Banpodong, Seocho-ku, \\ Seoul 137-040, Republic of Korea \\ ${ }^{2}$ Cancer Research Institute of Medical Science, Catholic University of Korea, 505 Banpodong, \\ Seocho-ku, Seoul 137-040, Republic of Korea \\ ${ }^{3}$ Department of Obstetrics and Gynecology, Catholic University of Korea, 505 Banpodong, \\ Seocho-ku, Seoul 137-040, Republic of Korea
}

\begin{abstract}
Since persistent infection with high-risk human papillomavirus (HPV) is a known cause of highgrade cervical intraepithelial neoplasia and cervical cancer, several HPV DNA detection methods have been developed during the last decade. The Hybrid Capture II (HCII) assay, which allows detection of 13 high-risk HPVs, has been well validated; however, it does not provide any genotype-specific information. The oncogenic activity of HPV is dependent on its genotype. The prophylactic effects of HPV vaccines are based on L1 virus-like particles and are limited mainly to infections corresponding to the HPV type used to develop the immunogen. Therefore, accurate detection and genotyping are important for treatment as well as screening. A newly developed HPV genotyping system using a liquid bead array was evaluated with 286 cervical samples and the results were compared to two commercially available methods, i.e. the HCIl and HPV DNA chip assays, and sequencing. The sensitivity for detection of high-risk HPV was $85.3 \%$ (HCII), 94.7\% (DNA chip) and $99.0 \%$ (liquid bead array). The liquid bead array showed almost perfect agreement $(\kappa=0.95)$ with genotype information confirmed by sequencing, while substantial agreement $(\kappa=0.8)$ was observed between DNA chip and sequencing. Furthermore, the liquid bead array had superior detection of 26 HPVs (16 high-risk and 10 low-risk types) and has proven to be as accurate as sequencing in identifying individual HPV types, even in cases with multiple HPV infections.
\end{abstract}

\section{INTRODUCTION}

Human papillomaviruses (HPVs) are causal agents involved in the development of carcinomas in the cervix uteri as well as pathological changes of the skin including mucosa, particularly warts, condylomas and dysplasias (Remmerbach et al., 2004). Due to the central role of HPV in anogenital carcinogenesis, HPV testing has received intensive scrutiny as an adjunct or replacement of cervical cytology analysis for cervical cancer screening (Coutlée et al., 2009). Currently, there are about 100 identified genotypes of HPV, of which about 40 are genital HPV types that invade the genital organs such as the uterine

Abbreviations: HCII, Hybrid Capture II; HPV, human papillomavirus; LSIL, low-grade squamous intraepithelial lesion; SCC, squamous cell cervical carcinoma; WNL, within normal limits. cervix, vaginal wall, vulva and penis (Kawana et al., 2009). Genital HPV types are classified into high-risk types associated with cervical cancer and low-risk types known as causative pathogens of condyloma acuminatum. Based on epidemiological studies, types $16,18,31,33,35,39,45$, $51,52,56,58,59,68,73$ and 82 have been classified as high risk, and types 26,53 and 66 as potential high risk, whereas types $6,11,40,42,43,44,54,61,70,72,81$ and 89 have been regarded as low risk (Muñoz et al., 2003).

The HPV prophylactic vaccine against types 16 and 18 has the potential to eliminate up to $70 \%$ of cervical cancers, depending on the coverage and acceptance of the vaccine (Bhatla \& Moda, 2009). Two prophylactic HPV vaccines have thus far been developed: Gardasil, a quadrivalent vaccine targeting HPV 6, 11, 16 and 18 (Villa et al., 2006), and Cervrix, a bivalent vaccine that targets HPV 16 and 18 
(Harper et al., 2006). However, these vaccines have negligible prophylactic effects on other HPV types (Ochi et al., 2008). Therefore, HPV typing will have to continue to deal with cancers caused by non-vaccine types as well as women already infected prior to vaccination. HPV typing also can be used for determination of the contribution of individual HPV types in infections involving multiple HPV types.

Currently, the most common tests used to detect genital HPV in cervical samples are hybridization assays such as the Hybrid Capture II (HCII) (Digene HPV test; Qiagen) assay, and PCR systems with the degenerate primer sets MY09/11 and GP5+/6 + (Remmerbach et al., 2004; Winder et al., 2009). The HCII assay is based on hybridization in a solution with a mixture of non-isotopic single-stranded full-length RNA probes against 13 highrisk types (HPV 16, 18, 31, 33, 35, 39, 45, 51, 52, 56, 58, 59, $68)$. This assay has been validated, detects several high-risk types in one reaction, uses a convenient format and avoids potential contamination, a known problem with PCRbased methods (Coutlée et al., 2005). However, it does not provide any genotype-specific information. Since the various high-risk HPVs differ in their oncogenic potential; improved risk stratification requires accurate information on HPV genotype involved in an infection.

In contrast to the HCII assay, the PCR-based assay can detect individual HPV types. HPV typing could improve the specificity of HPV DNA detection tests for clinical use, allow management of HPV-infected women according to the risk of high-grade lesions, evaluate type-specific HPV prevalence, assess the type-specific concordance among detection methods and monitor the duration of protection in vaccinated populations (Meijer et al., 2006). In most of the PCR-based HPV detection systems, a broad spectrum of HPV types is amplified by consensus primers, followed by detection with type-specific probes. Four consensus assays target conserved sequence in the HPV L1 gene. The PGMY09/11 (yielding a 450 bp amplicon), GP5+/6+ (yielding a $150 \mathrm{bp}$ amplicon) and SPF1/2 (yielding a $65 \mathrm{bp}$ amplicon) consensus primer sets can amplify a wide spectrum of up to 36, 37 and 43 genital genotypes, respectively (Gravitt et al., 2000; Van Doorn et al., 2002; Hesselink et al., 2006; Gillio-Tos et al., 2006). After amplification with consensus primers, HPV amplicons are genotyped with reverse hybridization on line filters or on microtitre plates. Typing of PCR products can also be carried out by oligonucleotide microarrays that use immobilized DNA probes specific for each HPV type.

Array technologies permit the use of a number of targets. The Luminex xMAP suspension array technology can simultaneously detect several HPV genotypes by using $5.6 \mu \mathrm{m}$ polystyrene microspheres that are internally dyed with various ratios of two spectrally distinct fluorophors (Jiang et al., 2006; Schmitt et al., 2006). A variety of HPV type-specific probes can be coupled to different bead sets with specific absorption spectra. These sets are combined to a suspension array and allow up to 100 different probes to be measured simultaneously in a single reaction (multiplexing). This technology can potentially be fully automated, dramatically decreasing the personnel cost component of the assay; this method has been used for the genotyping of 45 HPV types with PGMY09/11 PCR (Wallace et al., 2005), 25 HPV types with type-specific primers for the HPV-specific E6 and E7 genes (Han et al., 2006), 22 HPV types with GP5 + /6 + PCR (Schmitt et al., 2006), 15 HPV types with YBT L1/GP-1 PCR (Oh et al., 2007), and 18 HPV types with GP5 +/6 + PCR (Geraets et al., 2009). This multiplex HPV genotyping has been evaluated with other commercially available methods, such as the HCII assay, RFLP and the HPV DNA chip, as not able to guarantee absolute accuracy. Evaluation of the performance of an HPV detection system is most accurately performed with sequencing, which gives the most conclusive genotype information despite being the most labour-intensive method.

The goal of this study was to evaluate an HPV genotyping method using liquid bead array technology that allows for the detection of 26 HPVs (16 high-risk HPV types including $16,18,31,33,35,39,45,51,52,53,54,56,58$, 59, 66 and 68, and 10 low-risk HPV types including 6, 11, $34,40,42,43,44,55,67$ and 70) and compare the results with two commercially available methods, the HCII assay and the HPV DNA chip assay, and sequencing for HPV detection and genotyping in clinical samples. All genotyping results detected by HCII, DNA chip and the liquid bead array were confirmed by sequencing, and the analytical sensitivities and specificities of these methods were calculated based on genotype information confirmed by sequencing.

\section{METHODS}

Study subjects. A total of 624 clinical samples collected at the Catholic Medical University from February to October 2006 were prospectively included in this study. The specimens were obtained from patients in the Department of Obstetrics and Gynecology in accordance with procedures approved by the Institutional Review Board of the Catholic University of Korea. The disease status was assigned according to the International Federation of Gynecology and Obstetrics.

Sample collection and isolation of DNA. Cervical swabs were obtained with Cervex-Brush (Pappete; Wallach Surgical Devices). The brush was immediately rinsed into a vial of PreservCyt solution (Cytyc). To isolate DNA, $2 \mathrm{ml}$ cell suspension was transferred to a $2 \mathrm{ml}$ reaction tube and washed twice by centrifugation at 14000 r.p.m. for $2 \mathrm{~min}$, removal of the supernatant and resuspension of the pellet in $1 \mathrm{ml}$ PBS. The final pellet was resuspended in $200 \mu \mathrm{l}$ PBS and used for DNA isolation with the Qiagen DNA blood minikit (Qiagen) according to the manufacturer's instructions.

HCII assay. HPV detection by HCII was performed with the HCII assay system according to the manufacturer's (Digene Diagnostic) protocol. The isolated DNA from cervical samples was denatured at $65{ }^{\circ} \mathrm{C}$ for $45 \mathrm{~min}$ and hybridized under high stringency conditions with a mixture of RNA probes that detect 13 different carcinogenic HPV types (Table 1). The resultant DNA-RNA hybrids were captured 
on the surface of microtitre plate wells that were coated with antiDNA-RNA hybrid antibody. The immobilized hybrids were then reacted with an alkaline phosphatase-conjugated antihybrid mAb. Light intensity was measured with a luminometer. The positive cutoff value was set at $1 \mathrm{pg}$ HPV DNA $\mathrm{ml}^{-1}$ in each specimen.

HPV genotyping by DNA chip. An HPV DNA chip (MyGene) was used for HPV genotyping. This HPV DNA chip contained 24 typespecific probes that consist of 16 high-risk types and 8 low-risk types (Table 1). Based on the manufacturer's instructions, the isolated DNA was first amplified with a set of consensus primers GPd5 $+/ 6+$ that were directed to a highly conserved region of $\mathrm{L} 1$ gene $\left(\mathrm{GPd} 5+, 5^{\prime}\right.$ TTTKTTACHGTKGTDGATACYAC-3'; GPd6 + , 5'-GAAAHATAAAYTGYAADTCATAYTC- $\left.{ }^{\prime} ; \mathrm{k}=\mathrm{g} / \mathrm{t} ; \mathrm{h}=\mathrm{t} / \mathrm{a} / \mathrm{c} ; \mathrm{d}=\mathrm{a} / \mathrm{t} / \mathrm{g} ; \mathrm{y}=\mathrm{t} / \mathrm{c}\right) . \quad \beta$ Globin was amplified as the internal control in the PCR. The PCR products of all samples were detected by electrophoresis in a $2.5 \%$ agarose gel; the product size of HPV DNA was $150 \mathrm{bp}$.

The amplified DNA was labelled with Cy5-dUTP (MEN Life Science Products). The labelled product was denatured for $5 \mathrm{~min}$ at $95{ }^{\circ} \mathrm{C}$ then mixed with a hybridization solution (MyGene) followed by placement of the sample onto the DNA chip. Hybridization was carried out at $43{ }^{\circ} \mathrm{C}$ for $90 \mathrm{~min}$ and was followed by washing with $3 \times \operatorname{SSPE}\left(0.54 \mathrm{M} \mathrm{NaCl}, 30 \mathrm{mM} \mathrm{NaH} \mathrm{PO}_{4}, 3 \mathrm{mM} \mathrm{Na}{ }_{2}\right.$ EDTA pH 7.4) for $5 \mathrm{~min}$ and $1 \times \mathrm{SSPE}$ for $5 \mathrm{~min}$, and drying at room temperature. The hybridized HPV DNA was visualized using a DNA chip scanner (ScanArray Lite; GSI Lumonics).

Table 1. Distribution of HPV genotypes recognized by $\mathrm{HCll}$, HPV DNA chip and liquid bead array methods

\begin{tabular}{|c|c|c|c|c|}
\hline \multirow{2}{*}{$\begin{array}{l}\text { Oncogenic } \\
\text { potential }\end{array}$} & \multirow{2}{*}{$\begin{array}{c}\text { HPV } \\
\text { genotype }\end{array}$} & \multicolumn{3}{|c|}{ Genotyping method } \\
\hline & & HCII & DNA chip & Liquid bead array \\
\hline \multirow[t]{16}{*}{ High risk } & 16 & + & + & + \\
\hline & 18 & + & + & + \\
\hline & 31 & + & + & + \\
\hline & 33 & + & + & + \\
\hline & 35 & + & + & + \\
\hline & 39 & + & + & + \\
\hline & 45 & + & + & + \\
\hline & 51 & + & + & + \\
\hline & 52 & + & + & + \\
\hline & 53 & & + & + \\
\hline & 54 & & + & + \\
\hline & 56 & + & + & + \\
\hline & 58 & + & + & + \\
\hline & 59 & + & + & + \\
\hline & 66 & & + & + \\
\hline & 68 & + & + & + \\
\hline \multirow[t]{10}{*}{ Low risk } & 6 & & + & + \\
\hline & 11 & & + & + \\
\hline & 34 & & + & + \\
\hline & 40 & & + & + \\
\hline & 42 & & + & + \\
\hline & 43 & & + & + \\
\hline & 44 & & + & + \\
\hline & 55 & & & + \\
\hline & 67 & & & + \\
\hline & 70 & & + & + \\
\hline
\end{tabular}

HPV genotyping by a liquid bead array system. The bead-based array uses type-specific oligonucleotide probes for 26 different HPVs including 16 high-risk types and 10 low-risk types, and is based on the DNA sequences of the viral L1 gene, which were obtained from the HPV database (http://hpv-web.lanl.gov/) (Tables 1 and 2). These type-specific probes had $5^{\prime}$-amine modification for bead coupling as well as 15 bp oligo-dT sequences attached for hybridization flexibility. The modified probes were coupled to carboxylated beads (Luminex) by a carbodiimide base coupling procedure. The preparation of beads coupled with oligonucleotide was previously reported (Oh et al., 2007). Each bead carrying the type-specific oligonucleotide was finally mixed in equal proportion; the total concentration of oligonucleotide was $0.1 \mu \mathrm{M}$. This mixture is referred to as the bead mix.

Amplification of the L1 gene from $200 \mathrm{ng}$ genomic DNA isolated from cervical samples was carried out with the PGMY09/11 primer set. PCR conditions were as published for PGMY09/11 by Gravitt et al. (2000). For a positive PCR control, two primers were used for amplification of glyceraldehyde-3-phosphate dehydrogenase (GAPDH) sequences: GAPDH F, 5'-GAGTCAACGGATTTGGTCGT-3' (forward primer) and GAPDH R, 5'-TTGATTTTGGAGGCATCTCG-3' (reverse primer).

The PCR products of all samples were detected by electrophoresis in a $1.5 \%$ agarose gel; the product size of HPV DNA was $450 \mathrm{bp}$. After the PCR, a single strand PCR was carried out for labelling of the complementary sequences of the probe with biotin-14-dCTP (Invitrogen). The PGMY09/11 reverse primer set was used for the PCR product labelling. PCR components in $20 \mu \mathrm{l}$ PCR mixture were $0.05 \mu \mathrm{M}$ PGMY09, $50 \mu \mathrm{M}$ dATP, dGTP, dTTP mixture, $20 \mu \mathrm{M}$ biotin-14-dCTP, $75 \mathrm{mM}$ Tris/ $\mathrm{HCl}$ (pH 9.0), $20 \mathrm{mM} \mathrm{MgCl} 2,50 \mathrm{mM}$ $\mathrm{KCl}, 20 \mathrm{mM}\left(\mathrm{NH}_{4}\right)_{2} \mathrm{SO}_{4}, 1 \mathrm{U}$ Taq polymerase (Biotools) and $5 \mu \mathrm{l}$ amplified L1 fragment. A 5 min denaturation step at $94{ }^{\circ} \mathrm{C}$ was followed by 35 cycles of amplification: denaturation at $94{ }^{\circ} \mathrm{C}$ for $30 \mathrm{~s}$, annealing at $58{ }^{\circ} \mathrm{C}$ for $1 \mathrm{~min}$ and elongation at $72{ }^{\circ} \mathrm{C}$ for $2 \mathrm{~min}$.

Hybridization buffer $(21 \mu \mathrm{l} 2 \times$ EZway Hybrisol; Koma) and $1 \mu \mathrm{l} \mathrm{HPV}$ bead mix containing $6.75 \times 10^{4}$ beads $\left(2.5 \times 10^{3}\right.$ for each HPV type and control) were added to a labelling tube containing the PCR products. The hybridization was conducted in the same way as previously reported $(\mathrm{Oh}$ et al., 2007). After hybridization, samples were immediately transferred to a filter plate and washed three times with washing buffer $(0.2 \mathrm{M} \mathrm{NaCl}$, $0.1 \mathrm{M}$ Tris, $0.08 \%$ Triton $\mathrm{X}-100, \mathrm{pH} 8.0$ ) at room temperature. The beads were resuspended for $15 \mathrm{~min}$ in $100 \mu \mathrm{l}$ streptavidin-R-phycoerythrin (Strep-PE; Molecular Probes) and analysed for internal bead colour and R-phycoerythrin receptor fluorescence in the Luminex 100 IS system. The median reporter fluorescence intensity of at least 100 beads was calculated for each bead set in the sample.

Confirmation of HPV genotyping for the DNA chip and liquid bead array methods compared to DNA sequencing. The genotyping results for 286 samples that were HPV positive by both liquid bead array and DNA chip were confirmed by sequencing with typespecific primers. The DNA fragment amplified within the L1 HPV gene by consensus primers was used for sequencing. PCR products amplified were isolated from agarose gels using a gel extraction kit (Qiagen). A total of $20 \mu \mathrm{l}$ of amplimer solution was eluted and $3 \mu \mathrm{l}$ eluent at $10 \mathrm{ng} \mu \mathrm{l}^{-1}$ was used for direct sequencing with the type-specific primer based on the HPV genotype detected by DNA chip and bead-based array for the amplified PCR product. Sequencing reactions of double-stranded PCR products were performed with a dye terminator cycle sequencing kit (ABI Prism dRhodamine terminator cycle sequencing ready reaction kit; PE Applied Biosystems). The DNA sequences obtained were compared to GenBank sequences using the BLAST program from the National Center for Biotechnology Information website.

Cut-off definition and statistical analysis. Reactions of probes with PCR products derived from PGMY09/11 PCR on 200 ng HPV-negative 
Table 2. Type-specific oligonucleotide probes for 26 HPV genotypes

The high-risk HPVs are indicated in bold.

\begin{tabular}{|c|c|c|}
\hline HPV type & GenBank accession no. & Probe sequence $\left(5^{\prime} \rightarrow 3^{\prime}\right)$ \\
\hline 6 & X00203 & ATC CGT AAC TAC ATC TTC CAC ATA CAC CAA \\
\hline 11 & M14119 & ATC TGT GTC TAA ATC TGC TAC ATA CAC TAA \\
\hline 18 & X05015 & TGC TTC TAC ACA GTC TCC TGT A \\
\hline 31 & J04353 & TGT TTG TGC TGC AAT TGC AAA CAG TGA TAC \\
\hline 33 & M12732 & TGC ACA CAA GTA ACT AGT GAC AG \\
\hline 35 & M74117 & GTG CTG CTG TGT CTT CTA GTG A \\
\hline 39 & M62849 & TCT ACC TCT ATA GAG TCT TCC ATA CCT TCT \\
\hline 40 & X74478 & TGC CAC ACA GTC CCC CAC ACC AA \\
\hline 42 & M73236 & GCC ACT GCA ACA TCT GGT GAT A \\
\hline 43 & AJ620205 & TCT ACT GAC CCT ACT GTG CCC AGT A \\
\hline 44 & U31788 & GCC ACT ACA CAG TCC CCT CCG TCT A \\
\hline 53 & DQ486475 & TTT CTG CAA CCA CAC AGT CTA TGT CCA \\
\hline 54 & U37488 & TAC AGC ATC CAC GCA GGA TAG CTT \\
\hline 55 & U31791 & TGC TGC TAC AAC TCA GTC TCC ATC TAC A \\
\hline 56 & X74483 & ACT GCT ACA GAA CAG TAA GTA AA T ATG AT \\
\hline 58 & D90400 & TAT GCA CTG AAG TAA CTA AGG AAG GT \\
\hline 59 & X77858 & CTA CTT CTT CTA TTC CTA ATG TAT ACA CAC \\
\hline 66 & U31794 & TGC AGC TAA AAGC ACA TTA ACT AA \\
\hline 67 & D21208 & TCT GAG GAA AAA TCA GAG GCT \\
\hline 68 & AJ831568 & CTG AAT CAG CTG TAC CAA ATA TTT AT \\
\hline 70 & U22461 & TG CAC CGA AAC GGC CAT ACC T \\
\hline
\end{tabular}

genomic DNA was considered as the background values. In this study, the HPV-negative genomic DNA was extracted from human cervical cancer cell line C33A. The cut-off was defined for each HPV probe individually as the mean of the background plus three times the SDs of 19 replicates (data not shown).

Sensitivity and specificity were defined as the probability of predicting high-risk HPV and the probability of predicting low-risk HPV given true HPV types in samples showing HPV positivity in both DNA chip and liquid bead array, respectively. Here, the true HPV type is considered to be determined by sequencing. For example, assume that the DNA chip predicts 100 high-risk and 186 low-risk samples for the total of 286 samples. If the 100 high-risk samples consist of 44 true high-risk and 56 true low-risk samples, while the 186 low-risk samples are composed of 6 true high-risk and 180 true low-risk samples, the sensitivity and specificity for detection of high-risk HPV in the DNA chip are $88 \%$ $\{100 \times[44 /(44+6)]\}$ and $76 \%\{100 \times[180 /(56+180)]\}$, respectively.

Agreement between the HPV assays was assessed using the Cohen $\kappa$ statistic, with values of: 0 to 0.200 , indicating poor agreement; 0.21 to 0.40 , indicating fair agreement; 0.41 to 0.60 , indicating moderate agreement; 0.61 to 0.80 , indicating substantial agreement; and 0.81 to 1.00 indicating almost perfect agreement. Statistical analyses were performed with SPSS software version 10.0 (SPSS).

\section{RESULTS}

To evaluate the bead array for HPV typing in clinical samples, a total of 624 cervical samples were used. The
HPV genotyping was first carried out by the liquid bead array and the commercial HPV DNA chip with PCR products derived from the consensus primers on $200 \mathrm{ng}$ genomic DNA isolated from the cervical samples (Fig. 1). The GPd $5+/ 6+$ primers were used in the genotyping with the DNA chip according to the manufacturer's guidelines (see Methods for details). Out of 624 samples, the number of HPV-positive samples detected by the liquid bead array and the DNA chip was 303 and 295, respectively. A comparison of HPV genotyping was made for the 286 samples showing HPV-positive results by both genotyping systems.

\section{Comparison of the sensitivity and specificity of HCII, liquid array and DNA chip assays for high- risk HPV detection}

The sensitivity and specificity of three HVP detection systems, HCII, liquid bead array and DNA chip, for highrisk HPV detection were calculated based on the genotype information confirmed by sequencing. In each HPV detection system, the HPV high-risk positive samples were defined according to the probe system for the detection of high-risk HPV (HCII, 13 types; liquid bead array, 16 types; DNA chip, 16 types) (Table 1). The highest overall sensitivity $(99.0 \%)$ and specificity $(88.5 \%)$ were obtained 


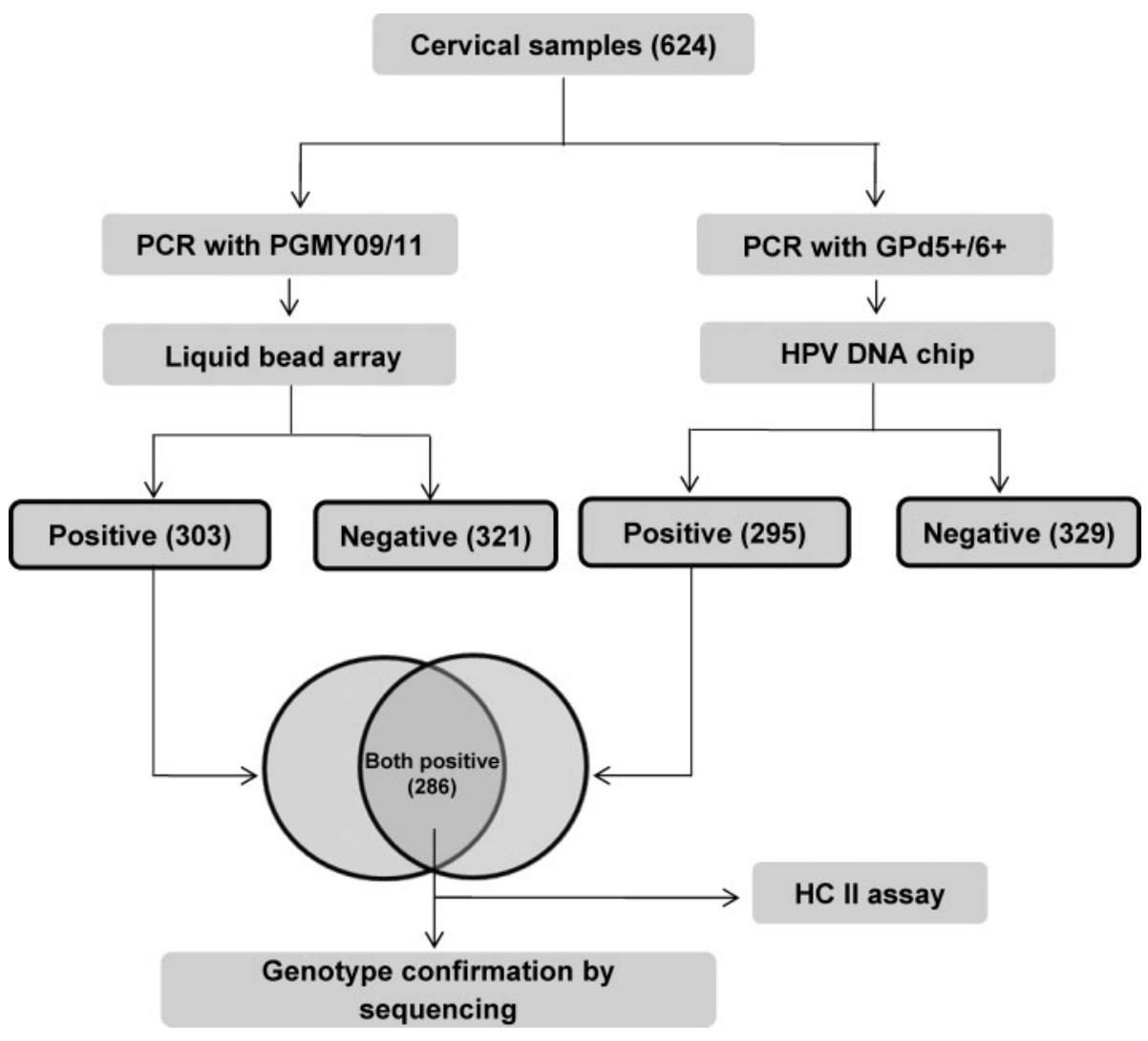

Fig. 1. HPV testing of clinical samples by three HPV detection systems: HCIl, DNA chip and liquid bead array assays. The numbers in parentheses represent the number of samples.

by the liquid bead array system while the lowest overall sensitivity $(85.3 \%)$ and specificity $(42.9 \%)$ were obtained by the HCII (Table 3). The sensitivity of HCII had significant variation according to the cytological diagnosis, whereas the liquid bead array showed almost constant sensitivity regardless of cytological diagnosis. The lowest specificity $(13.3 \%)$ was obtained in low-grade squamous intraepithelial lesions (LSILs) with the HCII assay; there were many false positives caused by cross-reactions. The HCII assay was designed to detect 13 high-risk types including HPV 16, 18, 31, 33, 35, 39, 45, 51, 52, 56, 58, 59 and 68. However, two additional high-risk HPVs, HPV 53 and 66, were also detected by HCII. Detection of these two high-risk HPVs by HCII was considered a false positive because they were not included in the probe system of the HCII.

The distribution of HPV types was surveyed for various stages of the cytological diagnosis on the basis of genotype information confirmed by sequencing. The most common

Table 3. Sensitivity and specificity of the three HPV detection systems for detection of high-risk HPVs

\begin{tabular}{|c|c|c|c|c|c|c|}
\hline \multirow[t]{2}{*}{ Cytology } & \multicolumn{2}{|c|}{ HCII } & \multicolumn{2}{|c|}{ DNA chip } & \multicolumn{2}{|c|}{ Liquid bead array } \\
\hline & Sensitivity (\%) & Specificity (\%) & Sensitivity (\%) & Specificity (\%) & Sensitivity (\%) & Specificity (\%) \\
\hline WNL & 77.4 & 68.8 & 90.1 & 100.0 & 98.6 & 100.0 \\
\hline ASCUS & 81.8 & 50.0 & 93.9 & 85.7 & 100.0 & 85.7 \\
\hline LSIL & 94.6 & 13.3 & 100.0 & 80.0 & 98.5 & 79.3 \\
\hline HSIL & 90.6 & 50.0 & 96.8 & 66.7 & 100.0 & 100.0 \\
\hline SCC & 100.0 & - & 100.0 & - & 100.0 & - \\
\hline Overall & 85.3 & 42.9 & 94.7 & 82.4 & 99.0 & 88.5 \\
\hline
\end{tabular}

ASCUS, Atypical squamous cells of undetermined significance; HSIL, high-grade squamous intraepithelial lesion. 
Table 4. Frequency of each HPV type at various cytological stages

The numbers in parentheses represent the percentages.

\begin{tabular}{|c|c|c|c|c|c|c|c|c|c|c|c|c|}
\hline \multirow[t]{3}{*}{ Cytology } & \multicolumn{10}{|c|}{ Single infection } & \multirow{3}{*}{$\begin{array}{l}\text { Multiple } \\
\text { infections }\end{array}$} & \multirow[t]{3}{*}{ Total } \\
\hline & \multicolumn{9}{|c|}{ High risk } & \multirow{2}{*}{$\begin{array}{l}\text { Low risk } \\
6,11,40 \text {, } \\
42,44,70\end{array}$} & & \\
\hline & 16 & 18 & 39 & 51 & 52 & 53 & 56 & 58 & Others & & & \\
\hline WNL & $20(16.0)$ & $12(9.6)$ & $3(2.4)$ & $6(4.8)$ & $6(4.8)$ & $15(12.0)$ & $8(6.4)$ & $11(8.8)$ & $14(11.2)$ & $17(13.6)$ & $13(10.4)$ & $125(100)$ \\
\hline LSIL & $14(21.5)$ & $5(7.7)$ & $6(9.2)$ & $1(1.5)$ & $4(6.2)$ & $4(6.2)$ & $4(6.2)$ & $3(4.6)$ & $9(13.8)$ & $4(6.2)$ & $11(16.9)$ & $65(100)$ \\
\hline HSIL & $13(35.1)$ & $2(5.4)$ & $0(0)$ & $2(5.4)$ & $0(0)$ & $0(0)$ & $1(2.7)$ & $5(13.5)$ & 7 (18.9) & $3(8.1)$ & $4(10.9)$ & $37(100)$ \\
\hline SCC & $9(69.2)$ & $1(7.7)$ & $0(0)$ & $0(0)$ & $1(7.7)$ & $0(0)$ & $0(0)$ & $0(0)$ & $1(7.7)$ & $0(0)$ & $1(7.7)$ & $13(100)$ \\
\hline
\end{tabular}

ASCUS, Atypical squamous cells of undetermined significance; HSIL, high-grade squamous intraepithelial lesion.

high-risk HPV was HPV 16 regardless of cytological diagnosis. The portion of HPV 16 and 18, in a single infection with high-risk types, increased with the severity of cervical lesion from $33.7 \%$ for WNL (within normal limits) to $83.3 \%$ for SCC (squamous cell cervical carcinoma) (Table 4). These findings show the association of HPV 16 and 18 with the severity of the cervical lesion. For the SCC samples, the HPV 16 accounted for $69.2 \%$ of all HPVs. A total of $63 \%$ of all low-risk HPVs and $37 \%$ of all multiple infections were observed in the WNL samples. In addition, $96 \%$ of all multiple infections included at least one high-risk HPV (data not shown). This finding indicates that the high-risk type of HPV might play an important role in multiple infections.

\section{Evaluation of HPV genotyping with the DNA chip and liquid bead array technology compared to sequencing}

In contrast to the HCII assay, DNA chip and liquid bead array technology can be used to identify 24 HPV genotypes; the latter can detect two additional HPVs, HPV 55 and 67 (Table 1). The genotyping performance for 24 common HPVs was used for the comparison. Both genotyping methods use type-specific probes; however, mistyping can occur due to non-specific reactions or cross-reactions. Sequencing provides the most accurate and conclusive genotype information despite being the most labour intensive. Therefore, all genotyping results for 286 samples by DNA chip and the liquid bead array were confirmed by sequencing with type-specific primers.

The overall strength of agreement between DNA chip results and sequencing was considered as substantial agreement $(\kappa=0.8)$, while HPV 40,45 and 54 showed fair agreement $(\kappa=0.33-0.39) \quad$ (Table 5). Almost perfect agreement was observed between the liquid bead array and sequencing $(\kappa=0.95)$. This indicates that the liquid
Table 5. Analysis of the concordance among DNA chip, liquid bead array and sequencing methods

\begin{tabular}{|c|c|c|c|}
\hline \multirow[t]{2}{*}{ HPV genotype } & \multicolumn{3}{|c|}{$\kappa$ value for HPV genotype } \\
\hline & $\begin{array}{l}\text { Liquid bead } \\
\text { array vs } \\
\text { sequencing }\end{array}$ & $\begin{array}{l}\text { DNA chip vs } \\
\text { sequencing }\end{array}$ & $\begin{array}{l}\text { Liquid bead } \\
\text { array vs } \\
\text { DNA chip }\end{array}$ \\
\hline \multicolumn{4}{|l|}{ High risk } \\
\hline 16 & 0.99 & 0.94 & 0.90 \\
\hline 18 & 0.96 & 0.88 & 0.90 \\
\hline 31 & 1.0 & 0.76 & 0.75 \\
\hline 33 & 1.0 & 0.77 & 0.63 \\
\hline 35 & 1.0 & 0.77 & 0.80 \\
\hline 39 & 0.96 & 0.92 & 0.89 \\
\hline 45 & 1.0 & 0.33 & 0.40 \\
\hline 51 & 0.90 & 0.60 & 0.60 \\
\hline 52 & 1.0 & 0.71 & 0.70 \\
\hline 53 & 0.97 & 0.66 & 0.73 \\
\hline 54 & 1.0 & 0.36 & 0.40 \\
\hline 56 & 1.0 & 0.88 & 0.88 \\
\hline 58 & 0.98 & 0.79 & 0.80 \\
\hline 59 & 1.0 & 0.89 & 0.72 \\
\hline 66 & 0.89 & 0.96 & 0.84 \\
\hline 68 & 0.91 & 0.95 & 0.88 \\
\hline \multicolumn{4}{|l|}{ Low risk } \\
\hline 6 & 0.81 & 0.83 & 0.81 \\
\hline 11 & 0.91 & 0.77 & 0.77 \\
\hline 34 & - & - & - \\
\hline 40 & 0.83 & 0.39 & 0.34 \\
\hline 42 & 1.0 & 0.83 & 0.83 \\
\hline 43 & - & - & - \\
\hline 44 & - & - & - \\
\hline 70 & 0.92 & 0.80 & 0.67 \\
\hline $\begin{array}{l}\text { Overall } \kappa \\
(95 \% \mathrm{CI})\end{array}$ & $\begin{array}{c}0.95 \\
(0.93-0.97)\end{array}$ & $\begin{array}{c}0.80 \\
(0.78-0.84)\end{array}$ & $\begin{array}{c}0.77 \\
(0.73-0.82)\end{array}$ \\
\hline
\end{tabular}

$95 \%$ CI, $95 \%$ Confidence interval. 
bead array had higher accuracy for HPV genotyping than DNA chip technology. The genotyping results compared between the liquid bead array and DNA chip showed substantial agreement $(\kappa=0.77)$. Fair agreement was observed in the comparison between DNA chip and the liquid bead array methods for HPV 40, 45 and 54, similar to the comparison between DNA chip and sequencing methods.

To evaluate the type specificity of each HPV probe for the two genotyping methods, the genotyping results were compared with genotypes confirmed by sequencing. The overall perfect match rate was 81.9 and $95.5 \%$ for the DNA chip and the liquid bead array methods, respectively (Tables 6 and 7). The diagonal number represents the frequency of perfect match while the off-diagonal number presents mismatches. Most of the mismatches were observed in cases with multiple infections. That is, the accuracy of typing tended to decrease with the number of
HPV types present in a sample (data not shown). The mismatch rate between high- and low-risk types was 5.4 and $1.1 \%$ for the DNA chip and the liquid bead array methods, respectively (Tables 6 and 7). The highest mismatch rate was observed for the HPV 40 and 53 by DNA chip technology.

\section{DISCUSSION}

Roles for HPV testing in clinical applications include: triage of equivocal cervical cytology results, primary screening as a standalone test or as an adjunct to cytology, and for follow-up of treated high-grade cervical intraepithelial neoplasia (CIN-2, 3). HPV testing is also essential for studies on the epidemiology and transmission of HPV infections, and the natural history of anogenital precancerous lesions and the efficacy of vaccination rely on the use of HPV DNA detection and typing methods (Coutlée et al.,

Table 6. Consistency of HPV typing between DNA chip and sequencing methods

The diagonal value represents the matched frequency of genotype pairs based on genotyping results obtained by DNA chip and sequencing methods; the off-diagonal value represents the unmatched frequency. The region with the genotype pairs of only high-risk HPVs is indicated in bold.

\begin{tabular}{|c|c|c|c|c|c|c|c|c|c|c|c|c|c|c|c|c|c|c|c|c|c|c|c|c|}
\hline \multirow{3}{*}{$\begin{array}{l}\text { HPV } \\
\text { genotype } \\
\text { confirmed by } \\
\text { sequencing }\end{array}$} & \multicolumn{24}{|c|}{ HPV genotyping by DNA chip } \\
\hline & \multicolumn{16}{|c|}{ High risk } & \multicolumn{8}{|c|}{ Low risk } \\
\hline & 16 & 18 & 31 & 33 & 35 & 39 & 45 & 51 & 52 & 53 & 54 & 56 & 58 & 59 & 66 & 68 & 6 & 11 & 34 & 40 & 42 & 43 & 44 & 70 \\
\hline \multicolumn{25}{|l|}{ High risk } \\
\hline 16 & 87 & 1 & & & & & & & & 1 & & & & & & & & & & & & & & \\
\hline 18 & & 28 & & & & & & & & 1 & & & & & & & & & & & & & & \\
\hline 31 & & 1 & 12 & 1 & & & & & & & & & & & & & & & & & & & & \\
\hline 33 & & 1 & & 7 & & & & & & & & & & & & & & & & & & & & \\
\hline 35 & & & & 1 & 5 & & & & 1 & & & & & & & & & 1 & & & & & & \\
\hline 39 & & & & 1 & & 12 & & & & & 1 & & & & & & & & & & & & & \\
\hline 45 & 1 & & & & & & 1 & & & & & & & & & & & & & & & & & \\
\hline 51 & 2 & & 1 & & & & & 7 & & & 1 & & 3 & & & & 1 & & & & & 1 & & \\
\hline 52 & & & 1 & & & & 2 & & 19 & 2 & & & 3 & & & 1 & & & 1 & & & & & 2 \\
\hline 53 & 3 & 1 & & & & & 1 & & & 23 & 1 & 1 & & & & & & & & 6 & & & 1 & 1 \\
\hline 54 & & & & & & & & & & & 2 & & & & & & & & & & & & & \\
\hline 56 & & & & & & & & & & & 2 & 16 & & & & & & & & & & 1 & & \\
\hline 58 & & 1 & & & & & & & 1 & & 1 & & 21 & & & & & & & & & & & \\
\hline 59 & 1 & & & & & & & & & & & & & 4 & & & & & & & & & & \\
\hline 66 & & & & & & & & & & 1 & & & & & 12 & & & & & & & & & \\
\hline 68 & & 1 & & & & & & & & & & & & & & 22 & & & & & & & & \\
\hline \multicolumn{25}{|l|}{ Low risk } \\
\hline 6 & & & & & & & & & & & & & & & & & 10 & & & & & & & 1 \\
\hline 11 & & & 1 & & & & & & & & & & & & & & 1 & 5 & & & & & & \\
\hline \multicolumn{25}{|l|}{34} \\
\hline 40 & & & & & & & & & & & & & & & & & 1 & & & 3 & 1 & & 1 & \\
\hline 42 & & & 1 & & & & & & & & & & & & & & & & & & 5 & & & \\
\hline \multicolumn{25}{|l|}{43} \\
\hline 44 & & & 1 & & & & & & & & 1 & & 1 & & & & & & & & & & & 2 \\
\hline 70 & & & & & & & & & & 1 & & & & & & & & & & & & & & 15 \\
\hline
\end{tabular}


Table 7. Consistency of HPV typing between liquid bead array and sequencing methods

The diagonal value represents the matched frequency of genotype pairs from genotyping results obtained by bead array and sequencing methods; the off-diagonal value represents the unmatched frequency. The region with the genotype pairs of only high-risk HPVs is indicated by bold.

\begin{tabular}{|c|c|c|c|c|c|c|c|c|c|c|c|c|c|c|c|c|c|c|c|c|c|c|c|c|}
\hline \multirow{2}{*}{$\begin{array}{l}\text { HPV } \\
\text { genotype } \\
\text { confirmed } \\
\text { by } \\
\text { sequencing }\end{array}$} & \multicolumn{24}{|c|}{ HPV genotyping by liquid bead array } \\
\hline & \multicolumn{16}{|c|}{ High risk } & \multicolumn{8}{|c|}{ Low risk } \\
\hline \multicolumn{25}{|l|}{ High risk } \\
\hline 16 & 88 & 1 & & & & & & & & & & & & & & & & & & & & & & \\
\hline 18 & & 30 & & & & & & & & & & & & & & & & & & & & & & \\
\hline 31 & & & 13 & & & & & & & & & & & & & & & & & & & & & \\
\hline 33 & & & & 10 & & & & & & & & & & & & & & & & & & & & \\
\hline 35 & & & & & 7 & & & & & & & & & & & & & & & & & & & \\
\hline 52 & & & & & & & & & 26 & & & & & & & & & & & & & & & \\
\hline 53 & & & & & & 1 & & & & 33 & & & & & & & & & & & & & & \\
\hline 54 & & & & & & & & & & & 2 & & & & & & & & & & & & & \\
\hline 56 & & & & & & & & & & & & 16 & & & & & & & & & & & & \\
\hline 58 & & & & & & & & & & & & & 23 & & & & & & & & & & & \\
\hline 59 & & & & & & & & & & & & & & 5 & & & & & & & & & & \\
\hline 66 & & & & 1 & & & & & & & & & & & 13 & & & & & & & & & \\
\hline 68 & & 1 & & & & & & & & 1 & & & & & & 10 & & & & & & & & \\
\hline \multicolumn{25}{|l|}{ Low risk } \\
\hline 6 & 1 & & & & & & & & & & & & & & & & 9 & & 1 & & & & & \\
\hline 11 & & & & & & & & & & & & & & & & & 1 & 5 & & & & & & \\
\hline \multicolumn{25}{|l|}{34} \\
\hline
\end{tabular}

2009). The results of this study show that about $90 \%$ of all HPV infections were caused by high-risk types of HPVs. This indicates that an HPV detection system should have high sensitivity for the detection of the high-risk types of HPVs. In this regard, HCII is a good method for HPV detection; it is the only HPV DNA test system currently approved by the Food and Drug Administration in the USA. It shows whether any of 13 high-risk types are present, but does not provide type-specific information. Since the various high-risk HPVs differ in their oncogenic potential, the information of HPV genotype is important. HPV typing could be used to evaluate the type-specific HPV prevalence and allow for the management of HPVinfected women according to the risk of high-grade lesions.

Therefore, the accurate identification of high-risk HPV genotypes is critical for defining a women's risk of progression to cervical cancer. Currently, most of the HPV genotyping methods are based on HPV DNA amplification by PCR with consensus primers. Consensus PCR assays have been developed for amplification in one reaction that includes the majority of known, as well as novel, anogenital HPV genotypes (Coutlée et al., 2009). After amplification with consensus primers such as MY09/ 11, PGMY09/11 or GP5+/6+, HPV amplicons were genotyped by reverse hybridization on line filters or microtitre plates. Typing assays using membrane-based reverse line blot methods are limited to a maximum of 40 probes per hybridization reaction. This restriction can be overcome with array technologies, such as the solid-phase microarray or liquid bead array. In addition, the arraybased HPV detection system can detect the presence of multiple HPV types at the same time.

Luminex xMAP suspension array technology can simultaneously detect several HPV genotypes using $5.6 \mu \mathrm{m}$ polystyrene microspheres. Suspension arrays have several advantages over microarrays; these include favourable 
hybridization kinetics that lead to shorter reaction times and a faster instrument read-out. These features of suspension arrays make large-scale epidemiological and vaccination studies possible. HPV genotyping by the liquid bead array have been reported elsewhere (Wallace et al., 2005; Schmitt et al., 2006; Han et al., 2006; Oh et al., 2007; Geraets et al., 2009); however, the performance was evaluated by commercially available methods, such as the HCII assay, RFLP and HPV DNA chip methods, which could not guarantee absolute accuracy.

A novel HPV genotyping system using liquid bead array technology has been developed and reported in this study. This system allows for the detection of 26 HPVs (16 highrisk HPV types and 10 low-risk HPV types). To evaluate clinical performance of the liquid bead array, the HPV genotyping results of the liquid bead array were compared to two commercially available HPV detection systems, i.e. HCII and HPV DNA chip methods, and the DNA sequencing method. The liquid bead array system demonstrated better performance than the two commercial HPV detection systems, the HCII and DNA chip methods. In addition, the accuracy of genotyping in the liquid bead array was comparable to that of the sequencing method $(\kappa=0.95)$ (Table 5$)$. The liquid bead array results also showed high accuracy for multiple infections (data not shown). Multiple infections were found to be common among high-risk populations and are associated with a greater risk of a poorer outcome. In addition, the oncogenic potential varies by HPV type and the HPV vaccine is type specific. Therefore, the accurate detection and typing of multiple infections are important for patient treatment.

The difference in the performance of HPV genotyping tests can significantly affect the results of clinical and epidemiological studies. Mistyping of high- and low-risk types might lead to more significant problems than mistyping among high-risk types. Mistyping between high- and lowrisk types was 5.4 and $1.1 \%$ for the DNA chip and the liquid bead array methods, respectively. Most of mistyping occurred in samples from multiple infections. The overall frequency of mistyping was 18.1 and $0.5 \%$ for DNA chip and the liquid bead array methods, respectively (Tables 6 and 7). The high-level mismatches with DNA chip technology might be due to the sequence similarity among the 24 probes designed against the $150 \mathrm{bp} \mathrm{L1}$ fragment, or suboptimal hybridization conditions. However, the genotyping accuracy of the liquid bead array was comparable to the accuracy of sequencing. These findings show that the liquid bead array was more accurate for HPV typing than DNA chip technology. The better performance of the liquid bead array might be due to the favourable hybridization kinetics, which closely approximately the kinetics of solution-phase hybridization.

The ideal HPV genotyping system should have accuracy comparable to sequencing, and should allow for rapid and simple genotyping. The results of this study suggest that the liquid bead array might be an excellent system for highly accurate HPV genotyping. In addition, it can be automated or deployed on a high-throughput platform, which is essential for an assay intended for large-scale epidemiological and vaccination studies.

\section{REFERENCES}

Bhatla, N. \& Moda, N. (2009). The clinical utility of HPV DNA testing in cervical cancer screening strategies. Indian J Med Res 130, 261-265.

Coutlée, F., Rouleau, D., Ferenczy, A. \& Franco, E. (2005). The laboratory diagnosis of genital human papillomavirus infections. Can J Infect Dis Med Microbiol 16, 83-91.

Coutlée, F., Mayrand, M., Roger, M. \& Franco, E. L. (2009). Detection and typing of human papillomavirus nucleic acids in biological fluids. Public Health Genomics 12, 308-318.

Geraets, D. T., Heideman, D. A. M., De Koning, M. N. C., Snijders, P. J. F., Van Alewijk, D. C. J. G., Meijer, C. J. L. M., Van Doorn, L. J. \& Quint, W. G. V. (2009). High-throughput genotyping of high-risk HPV by the digene HPV genotyping LQ test using GP5+/6+-PCR and xMAP technology. J Clin Virol 46, S21-S26.

Gillio-Tos, A., De-Marco, L., Ghisetti, V., Snijders, P. J., Segnan, N., Ronco, G. \& Merletti, F. (2006). Human papillomavirus typing with $\mathrm{GP} 5+/ 6+$ polymerase chain reaction reverse line blotting and with commercial type-specific PCR kits. J Clin Virol 36, 126-132.

Gravitt, P. E., Peyton, C. L., Alessi, T. Q., Wheeler, C. M., Coutlée, F., Hildesheim, A., Schiffman, M. H., Scott, D. R. \& Apple, R. J. (2000). Improved amplification of genital human papillomaviruses. J Clin Microbiol 38, 357-361.

Han, J., Swan, D. C., Smith, S. J., Lum, S. H., Sefers, S. E., Unger, E. R. \& Tang, Y.-W. (2006). Simultaneous amplification and identification of 25 human papillomavirus types with Templex technology. J Clin Microbiol 44, 4157-4162.

Harper, D. M., Franco, E. L., Wheeler, C. M., Moscicki, A. B., Romanowski, B., Roteli-Martins, C. M., Jenkins, D., Schuind, A., Costa Clemens, S. A. \& Dubin, G. (2006). Sustained efficacy up to 4.5 years of a bivalent L1 virus-like particle vaccine against human papillomavirus types 16 and 18: follow-up from a randomized control trial. Lancet 367, 1247-1255.

Hesselink, A. T., Bulkmans, N. W. J., Berkhof, J., Lorincz, A. T., Meijer, C. J. L. M. \& Snijders, P. J. F. (2006). Cross-sectional comparison of an automated hybrid capture 2 assay and the consensus GP5 +/6+ PCR method in a population-based cervical screening program. J Clin Microbiol 44, 3680-3685.

Jiang, H. L., Zhu, H. H., Zhou, L. F., Chen, F. \& Chen, Z. (2006). Genotyping of human papillomavirus in cervical lesions by L1 consensus PCR and the Luminex xMAP system. J Med Microbiol 55, 715-720.

Kawana, K., Yasugi, T. \& Taketani, Y. (2009). Human papillomavirus vaccines: current issues \& future. Indian J Med Res 130, 341-347.

Meijer, C. J., Snijders, P. J. \& Castle, P. E. (2006). Clinical utility of HPV genotyping. Gynecol Oncol 103, 12-17.

Muñoz, N., Bosch, F. X., De Sanjosé, S., Herrero, R., Castellsagué, X., Shah, K. V., Snijders, P. J. F., Meijer, C. J. L. M. \& International Agency for Research on Cancer Multicenter Cervical Cancer Study Group (2003). Epidemiologic classification of human papillomavirus types associated with cervical cancer. $N$ Engl J Med 348, 518-527.

Ochi, H., Kondo, K., Matsumoto, K., Oki, A., Yasugi, T., Furuta, R., Hirai, Y., Yoshikawa, H. \& Kanda, T. (2008). Neutralizing antibodies against human papillomavirus types $16,18,31,52$, and 58 in serum 
samples from women in Japan with low-grade cervical intraepithelial neoplasia. Clin Vaccine Immunol 15, 1536-1540.

Oh, Y., Bae, S. M., Kim, Y.-W., Choi, H.-S., Nam, G.-H., Han, S.-J., Park, C. H., Cho, Y., Han, B.-D. \& Ahn, W. S. (2007). Polymerase chain reaction-based fluorescent Luminex assay to detect the presence of human papillomavirus types. Cancer Sci 98, 549-554.

Remmerbach, T. W., Brinckmann, U. G., Hemprich, A., Chekol, M., Kühndel, K. \& Liebert, U. G. (2004). PCR detection of human papillomavirus of the mucosa: comparison between MY09/11 and GP5 + /6 + primer sets. J Clin Virol 30, 302-308.

Schmitt, M., Bravo, I. G., Snijders, P. J., Gissmann, L., Pawlita, M. \& Waterboer, T. (2006). Bead-based multiplex genotyping of human papillomaviruses. J Clin Microbiol 44, 504-512.

Van Doorn, L.-J., Quint, W., Kleter, B., Molijn, A., Colau, B., Martin, M. T., Kravang-In, Torrez-Martinez, N., Peyton, C. L. \& Wheeler, C. M.
(2002). Genotyping of human papillomavirus in liquid cytology cervical specimens by the PGMY line blot assay and the $\mathrm{SPF}_{10}$ line probe assay. J Clin Microbiol 40, 979-983.

Villa, L. L., Ault, K. A., Giuliano, A. R., Costa, R. L., Petta, C. A., Andrade, R. P., Brown, D. R., Ferenczy, A., Harper, D. M. \& other authors (2006). Immunologic responses following administration of a vaccine targeting human papillomavirus types $6 / 11 / 16$, and 18 . Vaccine 24, 5571-5583.

Wallace, J., Woda, B. A. \& Pihan, G. (2005). Facile, comprehensive, high-throughput genotyping of human genital papillomaviruses using spectrally addressable liquid bead microarrays. J Mol Diagn 7, 72-80.

Winder, D. M., Ball, S. L. R., Vaughan, K., Hanna, N., Woo, Y. L., Fränzer, J., Sterling, J. C., Stanley, M. A., Sudhoff, H. \& Goon, P. K. C. (2009). Sensitive HPV detection in oropharyngeal cancers. $B M C$ Cancer 9, 440. 